\title{
Investigation of the Effect of Montmorillonite on the Thermal Properties of Polyvinylpyrrolidone
}

\author{
Volodymyr Krasinskyi ${ }^{1, *}$, Solomiia Onysko ${ }^{2}$ \\ Lviv Polytechnic National University, Department of Chemical Technology of Plastics Processing, 12, Bandera Str., Lviv, 79013, Ukraine \\ Lviv Polytechnic National University, Department of Chemical Technology of Plastics, 12, Bandera Str., Lviv, 79013, Ukraine
}

\begin{abstract}
The influence of montmorillonite (MMT) on the thermal properties of polyvinylpyrrolidone (PVP) was studied by differential thermal and thermogravimetric analyses. It was found that the samples of the montmorillonite-polyvinylpyrrolidone mixture are characterized by higher thermal stability than the sample of pure PVP. It is shown that the degree of increase in the temperature of the beginning of destruction depends on the ratio of the mixture's components. It was found that the composition MMT:PVP $=1: 7$ has the highest heat resistance $\left(260^{\circ} \mathrm{C}\right)$, while pure PVP begins to degrade at a temperature of $200^{\circ} \mathrm{C}$.
\end{abstract}

Keywords: polyvinylpyrrolidone, montmorillonite, differential thermal analysis, thermal stability.

\section{Introduction}

Currently, the primary attention in creating polymer layered silicate nanocomposites is paid to achieving a high level of exfoliation of nanosized particles in the polymer matrix. Due to this, it is possible to obtain high-performance properties of composites. Therefore, the urgent problem is the selection of effective organomodifiers of layered silicate, providing high adhesion of the filler with the polymer matrix. In this aspect, the study of the influence of organoclay of different compositions on the obtained nanocomposites' structure and properties is of considerable interest. Identification of these patterns will expand the possibilities of controlling the structure and predicting composite materials' properties based on organoclay.

One of the approaches used to improve the thermodynamic compatibility of nonpolar polymer with layered silicates is the introduction of a polymer polar modifier.

Layered silicates have particular properties - a sharp drop in strength during wetting, liquefaction under dynamic conditions, swelling in the case of wetting, and shrinkage during drying. The hydrophilicity of aluminosilicates is the reason for their incompatibility with the organic polymer matrix - this is the main problem that must be overcome when creating polymer nanocomposites. This problem can be solved by modifying the clay with organic matter. Modified clay has the following advantages: 1) well dispersed in the polymer matrix; 2) interacts with the polymer chain [1-3].

Modification of aluminosilicates can be carried out by replacing inorganic cations inside the layers with organic cations [4]. Substitution with cationic surfactants (ammonium and phosphonium ions) increases the space between the layers, reduces the clay's surface energy, and gives the clay surface a hydrophobic character. Modified by the above method, the clays are better combined with polymers and form layered polymer nanocomposites. Along with ionic organic clay modifiers, nonionic modifiers that bind to the clay surface due to hydrogen bonds can be used. In some cases, organoclays obtained using nonionic modifiers are more chemically stable than organoclays obtained using cationic modifiers [5]. 
The study of the distribution of organoclay in the polymer matrix is of great importance, as the properties of the obtained composites directly depend on the degree of distribution of organoclay. The process of nanocomposite formation occurs through many intermediate stages [6]. In the first stage, the formation of a tactoid is observed - the polymer surrounds the agglomerates of organoclay. In the second stage, the polymer penetrates the interlayer space of the organic clay, resulting in the spread of layers up to 2-3 $\mathrm{nm}$. Further increase in the distance between the layers (third stage) leads to partial stratification and disorientation of the organoclay layers. Exfoliation or delamination is observed when the polymer spreads the clay layers by $8-10 \mathrm{~nm}$ or more [6].

All of these structures may be present in the resulting polymer nanocomposites, depending on the degree of distribution of the organic clay in the polymer matrix. The branched structure is the result of a very good degree of distribution of organoclay. Under conditions of excess organoclay and a poor degree of dispersion, organoclay agglomerates in the polymer matrix are possible, which is confirmed by X-ray structural analysis [7]. During the study of polymer nanocomposites, many specific methods are used to analyze the structure of the material [8].

We decided to use water-soluble polyvinylpyrrolidone (PVP) to intercalate montmorillonite and improve its compatibility with non-polar polymers. This work aimed to determine the effect of MMT on the heat resistance of polyvinylpyrrolidone by thermogravimetric (TGA) and differential thermal (DTA) methods.

\section{Experimental Section}

The following materials and reagents were used during the studies.

MMT $69911 \quad\left[\mathrm{Al}_{2} \mathrm{Si}_{4} \mathrm{O}_{10}(\mathrm{OH})_{2} \cdot \mathrm{nH}_{2} \mathrm{O}\right] \quad$ (Sigma-Aldrich), untreated, with a surface area of $250 \mathrm{~m}^{2} / \mathrm{g}$ and $\mathrm{pH}=5-8$.

PVP (LLC "AK Sintvita", Russia) with a molecular weight $12600 \pm 2700 \mathrm{~g} / \mathrm{mol}, \mathrm{pH}=3-8$, softening temperature $140-160^{\circ} \mathrm{C}, \rho^{20}=1190 \mathrm{~kg} / \mathrm{m}^{3}$ before use was dried under vacuum (13-15 Pa) at $60-70^{\circ} \mathrm{C}$ for 2-3 h.

Samples for research were prepared as follows. Aqueous solutions of PVP and MMT were mixed in appropriate concentrations. Before mixing with PVP, the colloidal solutions of MMT were treated with ul- trasound at a frequency of $22 \mathrm{kHz}$ for 3 min using the apparatus "Wave UZTA-0,4/22-OM" (Russia). The finished compositions were also sonicated for 15 minutes. After that, the mixture was dried in a vacuum at $80^{\circ} \mathrm{C}$, and the resulting films were ground in an agate mortar to obtain a fine powder.

Thermal analysis of both initial components and compositions based on them was performed on a derivatograph Q-1500D system F. Paulik, J. Paulik and L. Erdey, which allows for one sample to simultaneously determine weight loss (thermogravimetric TG) and thermal effects (differential -thermal analysis of DTA). The study was carried out in a dynamic mode in the air. The samples were heated at a rate of $2.5^{\circ} \mathrm{C} / \mathrm{min}$. The portion averaged $100 \mathrm{mg}$. The sensitivity of the channel on the TG scale was 100 mg, on the DTA scale - $250 \mu \mathrm{V}$, on the DTG scale $500 \mu \mathrm{V}$. Derivatographic studies of the samples were performed in the temperature range $50-400^{\circ} \mathrm{C}$.

The objects of research were: sample 1 - pure PVP, sample 2 - the composition of MMT:PVP $=1: 7$, sample 3 - MMT:PVP = 1:5, sample $4-$ MMT:PVP $=$ 1:3.

\section{Results and Discussion}

The results of differential thermal and thermogravimetric analyzes are presented in Figures 1 and 2 , respectively.

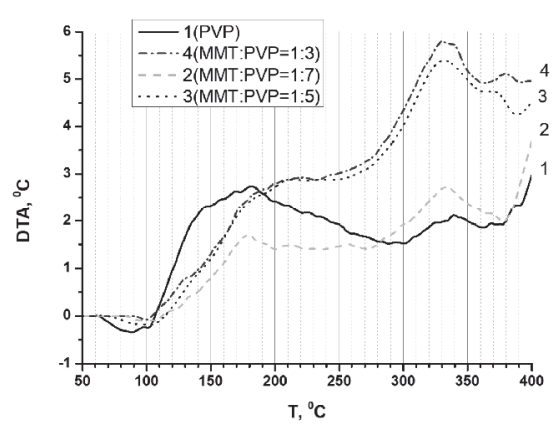

Figure 1: Differential thermal analysis of PVP and MPM: 1 - PVP; 2 - MMT:PVP = 1:7; 3 - MMT:PVP = 1:5; 4 - MMT:PVP = 1:3.

The loss of mass of sample $1(8 \%)$, sample 2 (1.5\%), sample $3(0.9 \%)$, and sample $4(4 \%)$ in the temperature range of $70-110^{\circ} \mathrm{C}$ (Fig. 2), which is accompanied by the appearance endothermic effect on the DTA curves (Fig. 1), corresponds to the release of free moisture from the compositions. Further weight loss of the samples in the temperature range of $120-150^{\circ} \mathrm{C}$ can be explained by the release 
of physically bound water. An exothermic effect is observed on the DTA curves of all samples (Figs. 1, 2), which can be explained by the predominant influence of oxidative processes in the PVP chain. It should be noted that these processes occur most intensively in sample 1 (PVP), as evidenced by the highest exothermic effect on the DTA curve. The least intense oxidative processes occur in sample 2 (MMT:PVP = 1:7), which is explained by the formation of a fluctuation network between PVP macromolecules and MMT plates during their mixing in the solution by ultrasonic treatment. The slightest exothermic effect appears on the DTA curve of this sample. The higher exothermal effect of samples 3 and 4 (MMT:PVP $=1: 5$ and MMT:PVP $=1: 3$ ) in this temperature range can be explained by the excess of MMT in the composition and the formation of a disordered structure.

The significant endothermic effect of sample 1
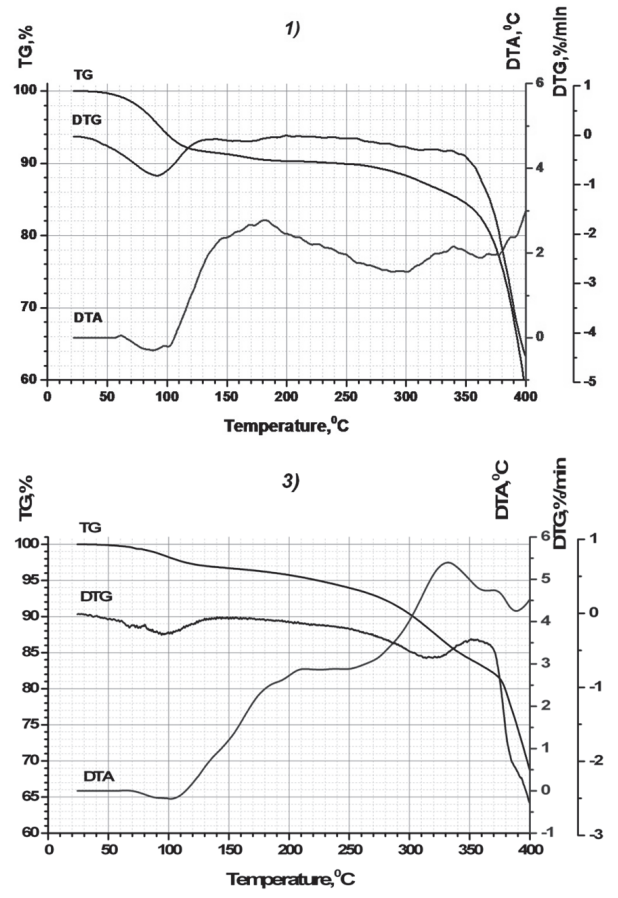

and weight loss (3.5\%) in the temperature range of $200-300^{\circ} \mathrm{C}$ is explained by destructive processes in the oxidized PVP chain. At the same time, for sample 2, there is almost no endothermic effect in the temperature range $200-260^{\circ} \mathrm{C}$, which is clearly expressed for sample 1. Slight weight loss (2\%) of sample 2 in this temperature range can be explained by the release of water from the composite structurally between the MMT plates. The destruction of sample 2 is shifted to the region of higher temperatures $260-280^{\circ} \mathrm{C}$ and is accompanied by a weight loss of $1.7 \%$ and the appearance of a slight endothermic effect on the DTA curve. Significantly higher heat resistance $\left(260^{\circ} \mathrm{C}\right.$ ) of sample $2(\mathrm{MMT}: \mathrm{PVP}=1: 7) \mathrm{com}$ pared to pure $\operatorname{PVP}\left(200^{\circ} \mathrm{C}\right)$ is a consequence of the formation of a homogeneous fluctuation net between PVP macromolecules and MMT layers, where dispersive particles of heat-resistant MMT block PVP chains.
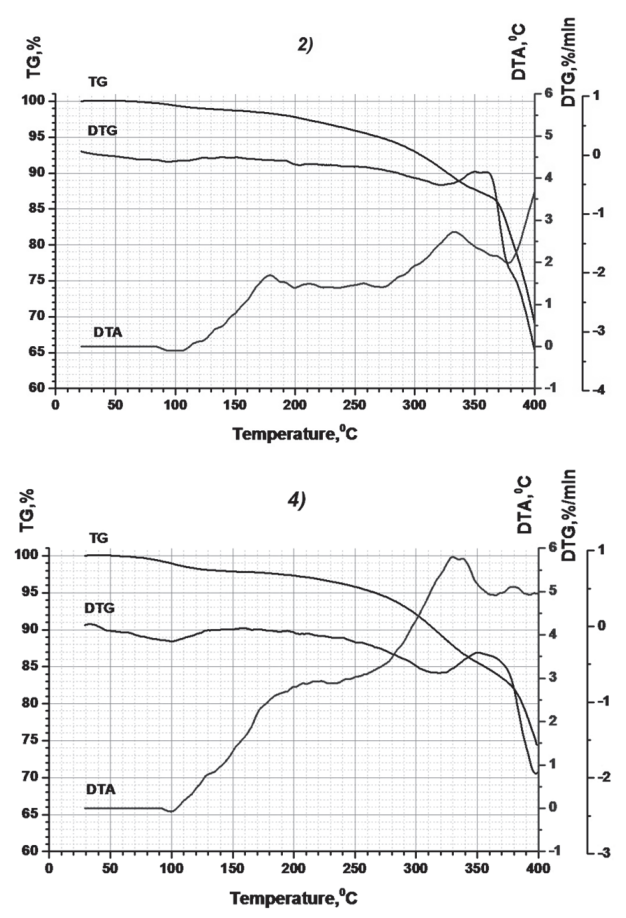

Figure 2: DTA and TG analyses of the composites: 1 - PVP; 2 - MMT:PVP=1:7; $3-$ MMT:PVP=1:5; $4-$ MMT:PVP=1:3

Thermal destruction of samples 3 and 4 is shifted to the region of lower temperatures than sample 2 and occurs in the range of $220-250^{\circ} \mathrm{C}$ and is accompanied by a weight loss of $1.5 \%$ and $1.7 \%$, respectively.

The exothermic effect on the DTA curve of sam- ple 1 in the temperature range of $320-350^{\circ} \mathrm{C}$, accompanied by a weight loss of the sample of $1.5 \%$, corresponds to the subsequent thermal-oxidative destruction of PVP chains. The beginning of thermal-oxidative processes in composite samples is shifted to the region of lower temperatures, which is 
explained by the acceleration of these processes under the influence of the solid surface of MMT. Thermal-oxidative destruction of sample 2 occurs in the temperature range $280-360^{\circ} \mathrm{C}$ and is accompanied by an apparent exothermic effect on the DTA curve with a maximum at a temperature of $335^{\circ} \mathrm{C}$ with a weight loss of $3.5 \%$. Thermal-oxidative destruction of samples 3 and 4 occurs in the temperature range of $250-360^{\circ} \mathrm{C}$. It corresponds to exothermic effects with maxima at a temperature of $330^{\circ} \mathrm{C}$ and is accompanied by intense weight loss - 10.8 and $12.2 \%$, respectively.

It should be noted that the intensive combustion of the PVP sample occurs at temperatures above $350^{\circ} \mathrm{C}$. According to the curve of DTG in the temperature range of $350-400^{\circ} \mathrm{C}$, the weight loss of the PVP sample is $22 \%$. The combustion processes of composites are shifted to the region of higher temperatures and according to the curves of DTG are observed at temperatures above $370^{\circ} \mathrm{C}$. In the temperature range of $370-400^{\circ} \mathrm{C}$, these samples lose weight less intensively than the PVP sample: sample 2 - 18\%, sample $3-14.5 \%$, sample $4-10.5 \%$.

\section{Conclusions}

Therefore, according to thermal analysis, the composition of MMT:PVP $=1: 7$ has higher heat resistance compared to PVP and compositions MMT:PVP $=1: 3$ and MMT:PVP $=1: 5$. The beginning of thermal destruction of the composition MMT:PVP $=1: 7$ is shifted to the region of higher temperatures $\left(260^{\circ} \mathrm{C}\right)$. For the sample PVP thermal destruction begins at $200^{\circ} \mathrm{C}$ and for samples 3 and 4 - at temperatures slightly higher than $220^{\circ} \mathrm{C}$. The presence of the solid phase of MMT in the samples of the compositions causes a shift in the temperature of the beginning of thermal-oxidative destructive processes in the region of lower temperatures compared to pure PVP. Burning of composite samples occurs at higher temperatures than pure PVP and is accompanied by less extreme weight loss.

\section{References and Notes}

1. Ahmad, M.B., Hoidy, W.H., Ibrahim, N.A.B. and Al-Mulla, E.A.J. (2009). Modification of montmorillonite by new surfactants. Journal of Engineering and Applied Sciences, 4, 184-188.

2. Kiliaris, P. and Papaspyrides, C.D. (2010). Polymer/layered silicate (clay) nanocomposites: An overview of flame retardancy. Progress in Polymer Science, 35, 902-958.
3. Mittal, V. (2009). Polymer Layered Silicate Nanocomposites: A Review. Materials, 2, 992-1057.

4. Carotenuto, G. (2010). Polymer-based nanocomposites. Polymer News. 26, 48-50.

5. Pavlidou, S. and Papaspyrides, C.D. (2008). A review on polymer-layered silicate nanocompopsites. Progress in Polymer Science, 32, 1119-1198.

6. Wagener, R. and Reisinger, T. (2003). Rheological method to compare the degree of exfoliation of nanocomposites, Polymer, 44, 7513-7518.

7. G. Cao. (2004). Nanostructures and Nanomaterials: Synthesis, Properties \& Applications. Imperial College Press, London, England.

8. Ślusarczyk, C., Biniaś, W., Fabia, J. and Biniaś, D. (2007). DSC and two-dimensional correlation infrared spectroscopy studies of PA6/montmorillonite composite fibres. Fibres \& Textiles in Eastern Europe, 5-6, 22-26. 